\title{
Large eyeballs in diving ichthyosaurs
}

\section{The huge eyes of these extinct reptiles may have been useful deep in the ocean.}

chthyosaurs are marine reptiles that existed about 250 million to 90 million years ago. They had fish-shaped bodies, which were exceptional among Mesozoic marine reptiles ${ }^{1}$. Here we report that ichthyosaurs also had huge eyeballs - larger than those of any other vertebrate. We infer that the genus Ophthalmosaurus, whose eyes were particularly large and sensitive, used to dive to depths of 500 metres or more.

Absolute size is an important property of eyes ${ }^{2-4}$, because larger eyes can house more retinal photoreceptive cells and receive more light per solid angle of image space $^{2-4}$. Eye size also usually reflects the importance of vision in animals ${ }^{4}$ : for example, the horse has among the largest eyeballs of any land animal alive today ${ }^{4}$, about 50 $\mathrm{mm}$ across, which may be important, given its fast speed $^{3}$. But eye size also scales with

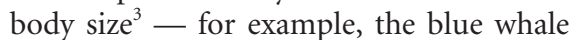
has the largest eyes of any living vertebrate ${ }^{4}$, about $150 \mathrm{~mm}$ across, although this is small for such a colossal body. These scaling effects should be considered when discussing eye size.

We used the sclerotic ring diameter to estimate the eyeball diameter of parvipelvians, an ichthyosaurian group with tuna-shaped bodies ${ }^{5}$ (Fig. 1), and compared its scaling with other tetrapods (Fig. 2). Eyeball diameters of tetrapods of a given body size are usually restricted within a narrow range 3 (Fig. 2). Parvipelvian ichthyosaurs, and some birds with sensitive vision, did not share this constraint, having large eyes relative to body length (Fig. 2).

The largest sclerotic ring we examined, $253 \mathrm{~mm}$ in its external diameter, belongs to Temnodontosaurus, which had a body length of about $9 \mathrm{~m}$. There also is a poorly known parvipelvian ichthyosaur that may have been $15 \mathrm{~m}$ long6, so the largest ichthyosaurian eye was probably more than $300 \mathrm{~mm}$ in diameter. The giant squid Architeuthis is thought to have the largest eyeball of any extant animal, having been estimated as approaching $250 \mathrm{~mm}$ in diameter ${ }^{7}$.

Ophthalmosaurus had the largest eyes (more than $220 \mathrm{~mm}$ in diameter) of any ichthyosaur for its body length (Fig. 2), and the largest sclerotic ring aperture, with a diameter of about $100 \mathrm{~mm}$. We estimated the

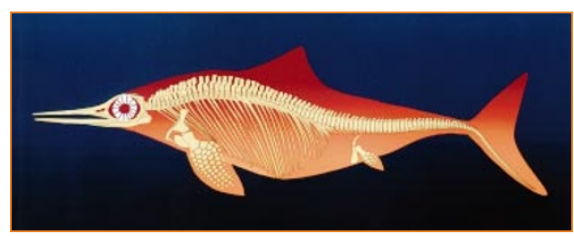

Figure 1 Artistic impression of the ichthyosaur Ophthalmosaurus. NATURE | VOL 402 | 16 DECEMBER 1999 | www.nature.com

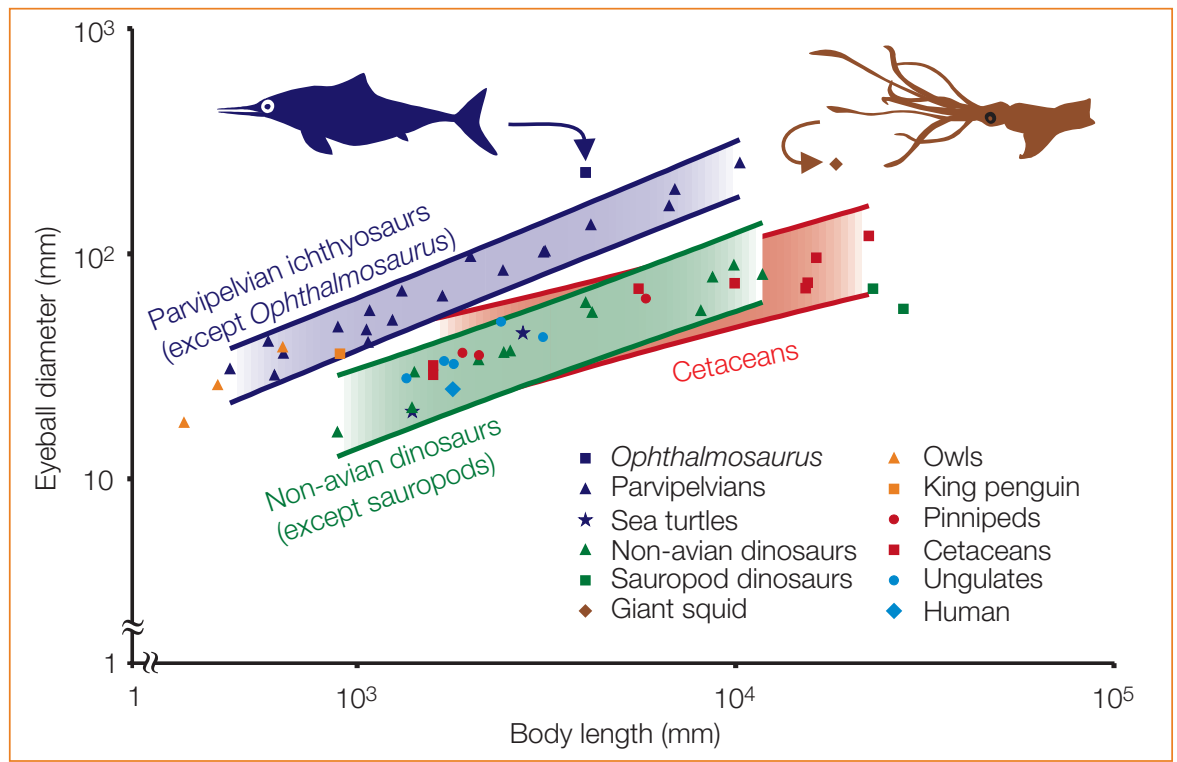

Figure 2 Logarithmic plot of eyeball diameter against body length. Bands show 95\% confidence ranges for the least-square regression lines for parvipelvian ichthyosaurs except Ophthalmosaurus $(n=19)$, non-avian dinosaurs except sauropods $(n=12)$, and cetaceans $(n=8)$. Eyeball diameters for dinosaurs and ichthyosaurs are based on the external diameter of the sclerotic rings (which were sometimes estimated from the height of the orbit in ichthyosaurs). Data for non-ichthyosaurs were derived from the literature.

minimum $f$-number (the same measure of relative aperture as is used for camera lenses) of several ichthyosaurian eyes (see Supplementary Information). The minimum $f$ numbers for typically nocturnal and diurnal vertebrate eyes are about 0.95 and 2.1, respectively ${ }^{3}$. The minimum $f$-number of an Ophthalmosaurus eye, the lowest of any ichthyosaur, was calculated to be between 0.76 and 1.1 , so the genus seems to have been capable of seeing in low-light conditions.

The large sclerotic ring aperture indicates that Ophthalmosaurus could probably detect point light sources, such as luminance from the photophores of $\mathrm{prey}^{8}$, a useful ability in the mesopelagic layer of the ocean (depths of 200 to 1,000 m). Cats, whose eyes have a similar minimum $f$ number, could theoretically see to a depth of $500 \mathrm{~m}$ in most oceans (based on data from refs 8-10; see Supplementary Information). Ophthalmosaurus was roughly $4 \mathrm{~m}$ long, with a mass of $930 \mathrm{~kg}$, comparable to the size of living mesopelagic diving animals ${ }^{11}$. Conservative estimates of diving duration and swimming speed indicate that it could dive to a depth of $600 \mathrm{~m}$ (see Supplementary Information).

To test whether Ophthalmosaurus was a deep diver, we examined the frequency of pathology arising from Caisson disease (also known as the 'bends') in the humeri and femora of various ichthyosaurs (see Supplementary Information). Deep-diving animals do not usually suffer from bends ${ }^{12}$, although some turtles do when an accident or escape response forces them to depart from their normal diving pattern, causing a high partial pressure of carbon dioxide in the blood ${ }^{13}$. We found that the two genera with the lowest minimum $f$-numbers had the highest frequencies of the bends.

Ryosuke Motani ${ }^{*} \$$, Bruce M. Rothschild $\dagger$, William Wahl Jr $\ddagger$

*University of California Museum of Paleontology, Berkeley, California 94720, USA

$\dagger$ The Arthritis Center of Northeast Ohio,

Youngstown, Ohio 44512, USA

$\ddagger$ Tate Geological Museum, Casper,

Wyoming 82601, USA

\$Present address: Department of Paleobiology, Royal Ontario Museum, Toronto,

Ontario M5S 2C6, Canada

e-mail:ryo.motani@utoronto.ca

1. Motani, R., You, H. \& McGowan, C. Nature 382, 347-348 (1996).

2. Martin, G. R. Prog. Sens. Physiol. 4, 43-81 (1983).

3. Hughes, A. in The Visual System in Vertebrates (ed. Crescitelli, F.) 613-756 (Springer, Berlin, 1977).

4. Walls, G. L. The Vertebrate Eye and its Adaptive Radiation (Cranbrook, Bloomfield Hills, 1942).

5. Motani, R. J. Vert. Paleontol. 19, 472-495 (1999).

6. McGowan, C. Can. J. Earth Sci. 33, 1011-1021 (1996).

7. Roper, C. F. E. \& Boss, K. J. Sci. Am. 246, 96-105 (1982).

8. Martin, G. R. Ibis 141, 444-450 (1999).

9. Jerlov, N. G. Marine Optics (Elsevier, Amsterdam, 1976). 10. Gunter, R. J. Physiol. (Lond.) 114, 8-15 (1951).

11.Schreer, J. F. \& Kovacs, K. M. Can. J. Zool. 75, 339-358 (1997).

12. Kooyman, G. L. \& Ponganis, P. J. Annu. Rev. Physiol. 60, 19-32 (1998).

13. Rothschild, B. M. Comp. Biochem. Physiol. 100, 529-535 (1991).

Supplementary information is available on Nature's World-Wide Web site (http://www.nature.com) or as paper copy from the London editorial office of Nature. 